\title{
THE NATIONAL CATARACT SURGERY SURVEY: I. METHOD AND DESCRIPTIVE FEATURES
}

\author{
PARUL COURTNEY \\ London
}

\begin{abstract}
SUMMARY
The National Cataract Surgery Survey is a prospective cross-sectional survey of surgery for age-related cataract within the National Health Service. It is the first national study of cataract surgery in the United Kingdom providing clinical data. This is the first in a series of papers and describes a profile of the characteristics of patients admitted for cataract surgery that includes: demography, referral sources, presence of co-existing ocular pathology, level of visual impairment on admission and waiting time for surgery. A profile of the process of the surgical procedure for 1990 is also described: number of operations performed, type of admission, type of anaesthetic, cataract extraction and intraocular lens and the grade of surgeon performing the procedure.
\end{abstract}

Surgical methods for cataract extraction have changed significantly since the introduction of microsurgical techniques and intraocular lens implantation, which have been uniformly available in recent times. It is possible that this may have also influenced the clinical indications for surgery. Age-related cataract constitutes the main surgical workload of ophthalmic services and the bulk of ophthalmic surgical waiting lists in the United Kingdom (UK). With an increasingly ageing population the demand for this surgical intervention is expected to rise.' Regular evaluation and audit of this common procedure is necessary for the provision of an accessible and acceptable surgical service to meet this demand.

The College of Ophthalmologists Cataract Audit aims to provide this assessment. Its objectives are to address the issues concerning the access, delivery and outcome of surgical services in the National Health Service (NHS) for age-related cataract in the UK, through a series of prospective audit studies. By the application of epidemiological methods it is anticipated that valid and relevant data will be collected that may ultimately influence health policy for the provision of cataract surgical services. The

Correspondence to: Parul Courtney, MSc, FRCS, FCOphth, College of Ophthalmologists, Bramber Court, 2 Bramber Road, London W14 9PQ, UK
National Cataract Surgery Survey is the first of these studies. The methods used and the descriptive features of the results are described in this first paper.

\section{OBJECTIVES OF THE NATIONAL CATARACT SURGERY SURVEY}

The primary objective of the National Cataract Surgery Survey was to obtain baseline data on current activity with respect to the access, delivery and outcome of cataract surgery, that was either not available or could not be obtained reliably from routine sources. Recent recommendations from the College ${ }^{2}$ and the Department of Health ${ }^{3}$ have stated that all doctors should now be involved in regular audit. The secondary objective of the Survey was to encourage and provide ophthalmologists with an opportunity to participate in an audit activity. It was organised such that it would be consultant led, so fulfilling the College's guidelines on ophthalmic medical audit. ${ }^{2}$

\section{METHOD}

The study design was that of a prospective cross-sectional survey. The sampling frame consisted of consultant ophthalmologists in the UK who performed surgery for agerelated cataract within the NHS. All consultants that fulfilled this criterion were invited to participate by providing clinical data on all patients admitted under their care for cataract surgery during the survey period. Consultants were classified as being not eligible for participation if they did not perform surgery for age-related cataract, only performed specialist surgery, were medical ophthalmologists, or were retired at the time of the Survey.

All adult NHS patients admitted for surgery for agerelated cataract were eligible for inclusion in the Survey. Those patients undergoing combined procedures or surgery for other types of cataract were excluded. This provided a cohort for studying the characteristics of patients admitted for cataract surgery and their experience with the existing surgical service.

The survey period was chosen arbitrarily to be week 48 of 1990, i.e. Monday 26 to Friday 30 November inclusive. 
Table I. Comparison of responders and non-responders

\begin{tabular}{|c|c|c|c|c|}
\hline \multirow[b]{2}{*}{ Characteristic } & \multicolumn{2}{|c|}{ Responders } & \multicolumn{2}{|c|}{ Non-responders } \\
\hline & $n$ & $\%$ & $n$ & $\%$ \\
\hline \multicolumn{5}{|l|}{ Type of hospital } \\
\hline Teaching & 83 & 23.8 & 36 & 20.2 \\
\hline District & 212 & 60.7 & 112 & 62.9 \\
\hline Eye & 54 & 15.5 & 30 & 16.9 \\
\hline Total & 349 & 100 & 178 & 100 \\
\hline & \multicolumn{4}{|c|}{ Chi-square $=0.893$, d.f. $=2, p=0.6$} \\
\hline \multicolumn{5}{|l|}{ Size of unit } \\
\hline 1 or 2 consultants & 87 & 24.9 & 47 & 26.4 \\
\hline 3 consultants & 99 & 28.4 & 40 & 22.5 \\
\hline 4 consultants & 57 & 16.3 & 28 & 15.7 \\
\hline$>4$ consultants & 106 & 30.4 & 63 & 35.4 \\
\hline Total & 349 & 100 & 349 & 100 \\
\hline & \multicolumn{4}{|c|}{ Chi-square $=2.607$, d.f. $=3, p=0.456$} \\
\hline \multicolumn{5}{|c|}{ Years since appointment } \\
\hline 5 & 93 & 23.3 & 41 & 26.3 \\
\hline 10 & 73 & 22.1 & 36 & 23.1 \\
\hline 15 & 59 & 17.8 & 32 & 20.5 \\
\hline 20 & 56 & 16.9 & 28 & 17.9 \\
\hline 25 & 42 & 12.7 & 14 & 8.97 \\
\hline 30 & 8 & 2.42 & 5 & 3.21 \\
\hline Total & 331 & 100 & 156 & 100 \\
\hline & \multicolumn{4}{|c|}{ Chi-square $=2.171$, d.f. $=5, p=0.825$} \\
\hline
\end{tabular}

Shortly before the survey period all eligible consultants were informed of its objectives and requested to indicate if they did not wish to participate, giving their reason(s) if possible. Each consultant was then informed of the survey period only a few days before the starting date to prevent changes in routine practice. Specific survey proformas for data collection were also provided at this time, together with notes on the definitions used and completion of proformas. Clinical data were collected on standardised proformas that were individually coded for each patient entered into the survey in order to maintain confidentiality.

Data relating to the pre-operative and peroperative periods were collected on admission (Part 1 of the proforma). These included information on patient demography, referral sources, level of visual impairment at first assessment in an out-patient department and its change with time to listing for surgery and admission, the presence of existing ocular pathology, the type of procedure

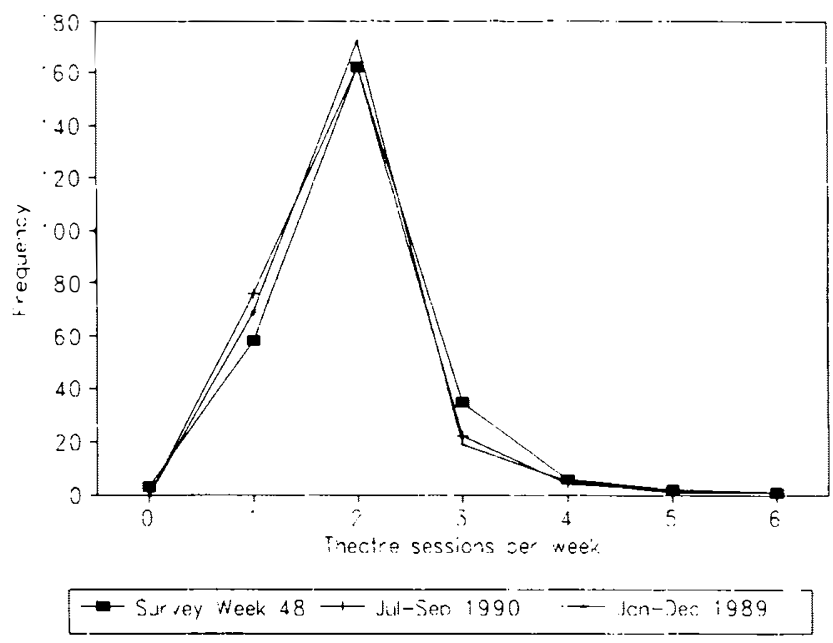

Fig. 1. Activity: theatre sessions. performed, details on peroperative management and the occurrence of complications both during surgery and in the immediate post-operative period. These data were to be collected prospectively when the patient was admitted for surgery. Only a minimal amount of data concerned with events prior to admission had to be obtained retrospectively, from the case notes or directly from the patient.

Data relating to the post-operative period were collected prospectively for up to 3 months after surgery (Part 2 of the proforma). The main outcome of interest was Snellen visual acuity, but the occurrence of complications at 3 months and the status of the patients at that time were also considered.

For each consultant routine data on numbers of theatre and out-patient sessions per week, length of surgical and out-patient waiting lists, and numbers of cataract operations performed were also requested on Part 3 of the proforma. These proforma were also individually coded for each consultant to maintain confidentiality. This information was requested for the cumulative quarters (January to September 1990) immediately prior to the Survey and for the whole of the previous year 1989.

All data returned to the College were entered onto a customised computer database using the Paradox 3.0 software and held in accordance with the Data Protection Act. Data return was slower than anticipated, and was finally closed in August 1991.

This paper focuses predominantly on descriptive analysis of the characteristics of patients admitted for cataract surgery and the surgical process. The $95 \%$ confidence intervals around estimates of prevalence were calculated by the normal approximation to the binomial distribution for large proportions and by the exact method for smaller ones. $^{4}$

\section{RESULTS}

At the time of the Survey there were 527 eligible consultants in the UK who were actively engaged in regularly performing surgery for age-related cataract. The response from all eligible consultant ophthalmic surgeons was $66.2 \%$. This accounted for $86 \%$ of all ophthalmic units

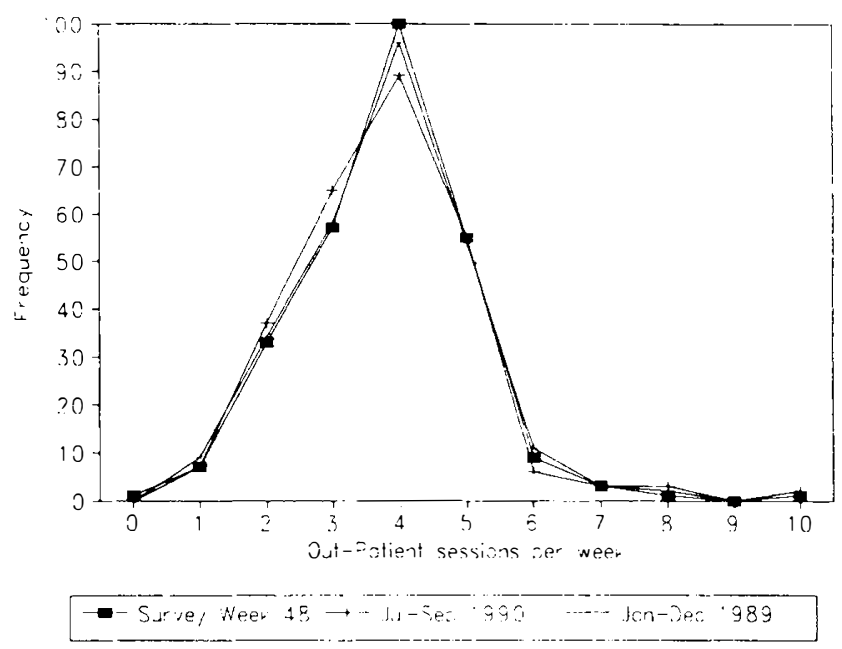

Fig. 2. Activity: out-patient sessions. 
Table II. Ethnic mix and occupation of patients

\begin{tabular}{|c|c|c|c|}
\hline & $n$ & $\%$ & $95 \% \mathrm{CI}$ \\
\hline \multicolumn{4}{|l|}{ (a) Ethnic group } \\
\hline Caucasian & 1387 & 96.1 & 95 to 97.1 \\
\hline Asian & 40 & 2.77 & 1.98 to 3.75 \\
\hline Afro-Caribbean & 16 & 1.11 & 0.64 to 1.79 \\
\hline Oriental & 0 & 0 & \\
\hline Other & 4 & & \\
\hline Not recorded & 33 & & \\
\hline Missing data & 18 & & \\
\hline Total & 1498 & 100 & \\
\hline \multicolumn{4}{|l|}{ (b) Occupation } \\
\hline Employed & 75 & 5.53 & 4.38 to 6.88 \\
\hline Unemployed & 12 & 0.884 & 0.45 to 1.54 \\
\hline Retired & 955 & 70.4 & 67.9 to 72.8 \\
\hline Housewife & 315 & 23.2 & 21.0 to 25.5 \\
\hline Not known & 83 & & \\
\hline Missing data & 58 & & \\
\hline Total & 1498 & 100 & \\
\hline
\end{tabular}

and represented every Regional Health Authority in the UK.

The response from consultants was considered first in terms of the type of hospital where they held their main appointment, secondly by the size of their ophthalmic unit, and thirdly by the number of years since their first appointment as a consultant ophthalmologist. The type of hospital was classified as being a teaching, district general or an eye hospital, and the size of an ophthalmic unit was classified by the number of consultants in the unit: less than or equal to two, three, four, or more than four. The proportions of responders and non-responders were very similar when compared in this way and no significant differences were demonstrated between the two groups (Table I).

Figs. 1 and 2 show the survey week in terms of activity, specifically the number of theatre and out-patient sessions for an individual consultant during the survey period, the weekly average for the cumulative quarters immediately prior to the survey week (January to September 1990) and the weekly average for the preceding year 1989. When considered in these terms the survey week did not exhibit any important differences with respect to activity in recent times.

A total of 1498 patients aged 50 years or more were admitted during the survey week and their study records were available for analysis for the pre- and per-operative data collected on the Part 1 proforma. Of these, 1182 records $(79 \%)$ were paired with post-operative data collected on the Part 2 proformas.

Table III. Waiting time for admission since listed for surgery

\begin{tabular}{lccc}
\hline Time (months) & $n$ & $\%$ & $95 \%$ CI \\
\hline Less than 3 & 442 & 30.1 & 27.8 to 32.5 \\
3 to 5 & 389 & 26.5 & 24.2 to 28.8 \\
6 to 8 & 202 & 13.8 & 12.0 to 15.5 \\
9 to 11 & 181 & 12.3 & 10.6 to 14.0 \\
12 or more & 254 & 17.3 & 15.4 to 19.2 \\
$\quad$ Total & 1468 & 100 & \\
\hline
\end{tabular}

\section{Patient Characteristics}

Demography. Nine hundred and nineteen females and 575 males ( 4 with sex unspecified) were admitted for surgery. The mean age of patients was 75.9 years (SD 9.59; 95\% confidence interval (CI) $75.4 \%$ to $76.4 \%$ ). The mean age for females was 76.8 years (SD $9.18 ; 95 \%$ CI $76.3 \%$ to $77.5 \%)$ and the mean age for males was 74.4 years (SD $10.0 ; 95 \%$ CI $73.6 \%$ to $75.3 \%$ ).

Table IIa shows that the patients were predominantly Caucasian while the main ethnic groups in the UK, namely Asian and Afro-Caribbean, together accounted for $3.9 \%$ of all patients admitted. Table IIb gives the distribution of patients by occupation. Two thirds were retired and one fifth described themselves as housewives.

Referral. The main source of first referral to an ophthalmic out-patient department was from the general practitioner $(82.7 \%)$. Ophthalmic medical practitioners and optometrists together accounted for $7.7 \%$ of the referrals and a further $7.8 \%$ were referred from 'other' departments within the hospital.

Waiting Time. Table III shows the time patients had waited for admission for surgery from the date they had been put on the waiting list. Fifty-six per cent of patients $(95 \% \mathrm{CI}$ $54.1 \%$ to $59.1 \%$ ) had waited less than 6 months for surgery, but $17.3 \%$ (95\% CI $15.4 \%$ to $19.2 \%$ ) had been waiting for 1 year or longer.

Co-existing Pathology. Table IV shows the main types of co-existing ocular pathology present on admission for cataract surgery. It describes the most severe type of pathology present in either eye of an individual patient, but does not give any indication of the severity of the pathological condition. If more than one type of pathology was present the most severe form was taken for that patient.

Over half of the patients $(56.8 \%$; $95 \%$ CI $54.2 \%$ to $59.4 \%$ ) had no co-existing pathology present. One hundred and seventy-three patients $(12.3 \% ; 95 \%$ CI $10.6 \%$ to $14.0 \%$ ) had some form of age-related maculopathy present. One hundred and forty-eight patients $(10.6 \%$; $95 \% \mathrm{CI}$ $8.92 \%$ to $12.1 \%$ ) had glaucoma, and 56 patients $(4 \% ; 95 \%$ CI 3.02 to 5.13) had some form of diabetic retinopathy.

Table IV. Ocular pathology on admission

\begin{tabular}{lrcc}
\hline Type of pathology & $\begin{array}{c}n \\
\text { (Patients) }\end{array}$ & $\begin{array}{c}\text { known } \\
\text { pathology }\end{array}$ & 95\% CI \\
\hline None present & 799 & 56.8 & 54.2 to 59.4 \\
Age-related maculopathy & 173 & 12.3 & 10.6 to 14.0 \\
$\quad$ Drusen/RPE changes & $(153)$ & $(10.9)$ & \\
$\quad$ Disciform & $(20)$ & $(1.4)$ & \\
Diabetic retinopathy & 56 & 4.0 & 3.02 to 5.13 \\
$\quad$ Background & $(30)$ & $(2.1)$ & \\
$\quad$ Proliferative & $(8)$ & $(0.6)$ & \\
$\quad$ Maculopathy & $(18)$ & $(1.3)$ & \\
Glaucoma & 148 & 10.6 & 8.92 to 12.1 \\
Amblyopia & 34 & 2.4 & 1.68 to 3.36 \\
Other & 197 & 14.1 & \\
Not known & 43 & - & \\
Missing & 48 & - & \\
Total & 1498 & 100 & \\
\hline
\end{tabular}


Table V. Visual impairment on admission

\begin{tabular}{|c|c|c|c|c|c|c|c|c|c|}
\hline \multirow[b]{2}{*}{ Visual acuity } & \multicolumn{3}{|c|}{ Age $<75$ years } & \multicolumn{3}{|c|}{ Age $75+$ years } & \multicolumn{3}{|c|}{ Total } \\
\hline & $n$ & $\%$ & $95 \% \mathrm{CI}$ & $n$ & $c \%$ & $95 \% \mathrm{CI}$ & $n$ & $\%$ & $95 \% \mathrm{CI}$ \\
\hline \multicolumn{10}{|l|}{ All persons } \\
\hline $6 / 6$ to $5 / 12$ & 337 & 58.7 & 54.6 to 62.7 & 315 & 40 & 36.6 to 43.4 & 6.52 & 47.8 & 4.5 .2 to 50.5 \\
\hline $6 / 18$ to $6 / 24$ & 124 & 21.5 & 18.1 to 24.8 & 260 & 33 & 29.8 to 36.3 & 384 & 28.4 & 25.8 to 30.6 \\
\hline $6 / 36$ to $6 / 60$ & 61 & 10.6 & 8.05 to 13.1 & 120 & 15.2 & 12.7 to 17.8 & 181 & 13.3 & 11.5 to 15.1 \\
\hline $3 / 60$ to NPL & 54 & 9.34 & 7.1 to $12 .()$ & 92 & 11.7 & 9.45 to 13.9 & 146 & 10.7 & 9.07 to 12.4 \\
\hline Total & 576 & & & 787 & & & 1363 & & \\
\hline \multicolumn{10}{|l|}{ Feniales } \\
\hline $6 / 6$ to $6 / 12$ & 167 & 53.2 & 47.7 to 58.7 & 196 & 37.7 & 33.5 to 41.9 & 363 & 43.5 & 40.2 to 46.9 \\
\hline $6 / 18$ to $6 / 24$ & 81 & 25.8 & 21.0 to $3(0.6$ & 177 & 34.4 & 30.0 to 38.1 & 258 & 30.9 & 27.8 to 34.1 \\
\hline $6 / 36$ to $6 / 60$ & 35 & 11.1 & 7.67 to 14.6 & 87 & 16.7 & 13.5 to 19.9 & 122 & 14.6 & 12.2 to 17.0 \\
\hline $3 / 60$ to NPL & 31 & 9.87 & 6.81 to 13.7 & 60 & 11.5 & 8.79 to 14.3 & 91 & 10.9 & 8.8 to 13.0 \\
\hline Total & 314 & & & 520 & & & 834 & & \\
\hline \multicolumn{10}{|l|}{ Males } \\
\hline $6 / 18$ to $6 / 24$ & 43 & 16.4 & 11.9 to 20.9 & 83 & 31.2 & 25.7 to 36.9 & 126 & 23.9 & 20.3 to 27.6 \\
\hline $6 / 36$ to $6 / 60$ & 26 & 9.92 & 6.59 to 14.2 & 33 & 12.5 & 8.48 to 16.4 & 59 & 8.5 & 8.50 to 13.9 \\
\hline $3 / 60$ to NPL & 23 & 8.78 & 5.65 to 12.9 & 32 & 12.1 & 8.15 to $16 .()$ & 55 & 7.83 & 7.83 to 13.0 \\
\hline Total & 262 & & & 265 & & & 527 & & \\
\hline
\end{tabular}

Thirty-four patients (2.4\%; $95 \% \mathrm{CI}$ interval 1.68 to 3.36 ) had amblyopia.

The 'other' category included a wide variety of conditions, consisting predominantly of the following: corneal pathology (scarring secondary to infections/inflammations, dystrophies), retinal degenerations, vasculopathies and old retinal detachments, pseudophakia and aphakia and common lid disorders.

Visual Impairment and Blindness. When the level of visual impairment on admission was considered, the visual acuity for the individual patient was taken to be that recorded for the best vision in the better eye. This would indicate the visual impairment experienced by the patient during the course of his or her daily life.

Using World Health Organisation criteria, 124 patients $(9.1 \% ; 95 \% \mathrm{CI} 7.6 \%$ to $10.7 \%)$ were blind on admission, having a visual acuity of less than $3 / 60$, and 335 patients (24.6\%; $95 \%$ CI $22.3 \%$ to $26.9 \%$ ) were classified as having low vision (visual acuity less than $6 / 18$ but better than and including 3/60). Using the United States (US) legal definition of blindness as being a visual acuity of less than $6 / 36$, there were 213 patients who were blind on admission (15.6\%; $95 \%$ CI $13.7 \%$ to $17.6 \%)$. Using the US definition for visual impairment (visual acuity being less than 6/12 and better than 6/60), 497 patients were in this category (36.5\%; $95 \%$ CI interval $33.9 \%$ to $39 \%$ ). Table $\mathrm{V}$ describes the level of visual impairment present on admission in greater detail for the age groups of less than 75 years and of 75 years and over.

Using the US definitions of blindness and visual impairment, $59 \%$ of the patients classified as blind and $42 \%$ of those classified as visually impaired had some pathology other than cataract in the eye providing the best corrected vision (Table VI).

\section{Characteristics of the Surgical Procedure}

A total of 1445 operations were performed during the survey week. Twenty patients (1.4\%) had surgery cancelled for medical reasons and all of these were planned inpatients. Nine patients $(0.6 \%)$ had surgery cancelled for some other reason, and these were evenly distributed between in-patients and day-cases. (Twenty-four patients did not have this information recorded.)

Table VI. Pathology in patients blind or visually impaired on admission (US definitions)

\begin{tabular}{|c|c|c|c|c|c|c|}
\hline \multirow[b]{2}{*}{ Pathology } & \multicolumn{3}{|c|}{ Blind } & \multicolumn{3}{|c|}{ Visually impaired } \\
\hline & $n$ & $\%$ & $95 \% \mathrm{CI}$ & $n$ & $\%$ & $95 \% \mathrm{CI}$ \\
\hline None & 72 & 40.9 & 33.6 to 48.2 & 268 & 57.9 & 53.4 to 62.4 \\
\hline Age-related maculopathy & 31 & 17.6 & 12.0 to 23.2 & 78 & 16.8 & 13.4 to 20.3 \\
\hline Drusen/RPE changes & (24) & & & 74 & & \\
\hline Disciform & (7) & & & 4 & & \\
\hline Diabetic retinopathy & 13 & 7.4 & 3.9 to 12.3 & 18 & 3.9 & 2.3 to 6.1 \\
\hline Background & (4) & & & 12 & & \\
\hline Proliferative & (2) & & & 1 & & \\
\hline Maculopathy & (7) & & & 5 & & \\
\hline Glaucoma & 24 & 13.6 & 8.6 to 18.7 & 57 & 12.3 & 9.3 to 15.3 \\
\hline Amblyopia & 4 & 2.3 & 0.6 to 5.7 & 2 & 0.4 & 0.05 to 1.5 \\
\hline Other & 32 & 18.2 & 12.5 to 23.9 & 40 & 8.6 & 6.2 to 11.6 \\
\hline Total & $176^{\prime \prime}$ & 100 & & $463^{\mathrm{h}}$ & 100 & \\
\hline
\end{tabular}

${ }^{4} 37$ records had missing data for this field. ${ }^{\mathrm{h}} 34$ records had missing data for this field. 
Table VII. Administration of antibiotics

\begin{tabular}{|c|c|c|c|c|c|c|c|c|}
\hline \multirow[b]{2}{*}{ Antibiotic } & \multicolumn{8}{|c|}{ Type of cataract extraction $(n)$} \\
\hline & \multicolumn{2}{|c|}{ ECCE } & \multicolumn{2}{|c|}{ ICCE } & \multicolumn{2}{|c|}{ Other ECCE } & \multicolumn{2}{|c|}{ Total } \\
\hline Yes & $67 \%$ & $(880)$ & $52 \%$ & (29) & $73 \%$ & $(40)$ & $67 \%$ & (949) \\
\hline No & $33 \%$ & $(428)$ & $48 \%$ & (27) & $27 \%$ & $(15)$ & $33 \%$ & $(470)$ \\
\hline Total & $100 \%$ & $(1308)$ & $100 \%$ & (56) & $100 \%$ & $(55)$ & $100 \%$ & (1419) \\
\hline None & $3 \%$ & $(33)$ & $2 \%$ & (1) & $7 \%$ & $(4)$ & $3 \%$ & $(38)$ \\
\hline Topical & $15 \%$ & (189) & $2 \%$ & (1) & $7 \%$ & (4) & $13 \%$ & $(194)$ \\
\hline Topical and steroid & $6 \%$ & $(81)$ & $9 \%$ & (5) & 0 & $(0)$ & $7 \%$ & (86) \\
\hline Subconjunctival & $21 \%$ & $(276)$ & $38 \%$ & (21) & $9 \%$ & (5) & $21 \%$ & $(302)$ \\
\hline Subconjunctival and steroid & $55 \%$ & $(715)$ & $49 \%$ & (27) & $76 \%$ & (42) & $56 \%$ & $(784)$ \\
\hline Total & $100 \%$ & $(1294)$ & $100 \%$ & (55) & $100 \%$ & $(55)$ & $100 \%$ & (1404) \\
\hline
\end{tabular}

ECCE, extracapsular cataract extraction; ICCE, intracapsular cataract extraction.

Fifty-nine per cent of operations were performed by surgeons at consultant grade, and $35 \%$ by the resident staff who included senior registrars $(10 \%)$, registrars $(16 \%)$ and senior house officers (9\%). Associate specialists, clinical assistants and locums collectively performed $6 \%$ of operations.

Sixty-eight per cent of patients had surgery for the first eye. Eight per cent of all patients admitted had day-case surgery and of these $95 \%$ had a local anaesthetic. Of the remainder that had in-patient surgery, $42 \%$ had a local and $58 \%$ had a general anaesthetic. Overall $54 \%$ had a general anaesthetic and $46 \%$ had a local anaesthetic.

Two thirds of patients received pre-operative topical antibiotic, and over half received subconjunctival antibiotic with steroid during the surgical procedure. Table VII shows the administration of antibiotic by type of procedure performed.

Ninety-two per cent of patients had a conventional extracapsular cataract extraction, $4 \%$ had an intracapsular extraction and $4 \%$ had some other form of extracapsular extraction (e.g. phacoemulsification). Table VIII shows the type of intraocular lens implant inserted and type of extraction performed for those patients who had this data recorded. Ninety-two per cent had a posterior chamber intraocular lens implant, $6 \%$ had an anterior chamber intraocular lens implant and $2 \%$ did not have any type of lens implant inserted.

\section{DISCUSSION}

No real differences between responders and non-responders were demonstrated when factors such as type of hospital, size of unit and length of time as a consultant were considered. The survey period was shown not to be an atypical period of activity when compared with recent times (January to September 1990 and the whole of 1989) in terms of the number of theatre and out-patient sessions available to the consultant. Consequently both the response and the survey period may be considered as a representative sample.

A profile of the characteristics of patients admitted for surgery for age-related cataract in the UK has been quantified and described for the first time. The sample represents those patients who have recognised they have a visual problem, have been identified as having a visual problem at the primary care level, been assessed at secondary care level within the hospital eye service and have been able to receive treatment. No direct comparisons for visual impairment, blindness, or prevalence of co-existing ocular pathology can be made with other epidemiological surveys that have been designed to quantify the prevalence and causes of visual impairment and blindness in communities. Also, the Survey was not designed to determine the severity of the type of pathology present, but only to indicate the distribution of the common conditions present in this group of patients.

By US definitions $15.6 \%$ of patients were blind and $36.5 \%$ were visually impaired on admission. The presence of pathology other than cataract does not entirely explain why $15 \%$ of patients are blind in the better eye as the distribution of co-existing pathology is similar in these two groups (Table VI).

A profile of the national experience of the process of the surgical procedure for age-related cataract has been described for 1990. If the working year for any hospital or ophthalmic department is considered to be 48 weeks, then from the number of operations performed during the sur-

Table VIII. Type of cataract extraction and intraocular lens implant (IOL)

\begin{tabular}{|c|c|c|c|c|c|c|c|c|}
\hline \multirow{3}{*}{$\frac{\text { Type of IOL }}{\text { Posterior chamber }}$} & \multicolumn{8}{|c|}{ Type of cataract extraction $(n)$} \\
\hline & \multicolumn{2}{|c|}{ ECCE } & \multicolumn{2}{|c|}{ ICCE } & \multicolumn{2}{|c|}{ Other ECCE } & \multicolumn{2}{|c|}{ Total } \\
\hline & $95 \%$ & $(1251)$ & $13 \%$ & (7) & $89 \%$ & $(50)$ & $92 \%$ & $(1308$ \\
\hline Anterior chamber & $3 \%$ & (35) & $69 \%$ & (38) & $11 \%$ & (6) & $6 \%$ & $(79$ \\
\hline None & $2 \%$ & (26) & $18 \%$ & (10) & 0 & (0) & $2 \%$ & (36 \\
\hline Total & $100 \%$ & $(1312)$ & $100 \%$ & (55) & $100 \%$ & (56) & $100 \%$ & $(1423$ \\
\hline
\end{tabular}

ECCE, extracapsular cataract extraction; ICCE, intracapsular cataract extraction. 
vey week, it is estimated that about 105090 were performed annually in the UK for age-related cataract, by all consultants who regularly undertake this procedure. This amounts to 199 cataract operations per consultant per year, or about 4 per week.

In the United States of America (USA) it is estimated that about 1 million operations are performed annually. ${ }^{5}$ The proportion of the population aged 50 years and over in 1990 is estimated to be $31 \%$ ( 18 million) in the UK and 26\% (65 million) in the USA. Given these figures, the number of patients having surgery is over two and a half times greater in the USA: 584 per 100000 of the population of 50 years of age or more have a cataract operation in the UK compared with 1539 per 100000 persons in the USA. It is possible that this may be due to differences in patient demand and expectation for good vision, differences in the threshold at which surgery is offered and differences in the provision of services.

The Survey was conducted before Audit Commission recommendations for increasing the level of day-case surgery for cataract had time to be implemented. ${ }^{6}$ The vast majority of patients were admitted as in-patients, with only $8 \%$ of all operations for age-related cataract performed as day-cases. Comparisons with other sources are not possible since routine data are not available for the type of admission by procedure performed and data from other studies report the experience of an individual consultant or ophthalmic unit.

Fifty-four per cent of patients had the operation performed under a general anaesthetic. This high proportion is not reflected in the results of a recent survey of consultant ophthalmologists in England and Wales that was carried out to ascertain their preferred methods for cataract extraction. The consultants were asked to describe the procedures they felt were usually undertaken for their patients, and not what actually happened to their patients. Thirty-seven per cent of consultants indicated that they used general anaesthesia for over $75 \%$ of their patients.

Apart from observing that $4 \%$ of patients had a planned intracapsular extraction, other comments on the reasons for this cannot be made from the data available from the Survey. This figure is higher than that recently reported for England and Wales, where $2 \%$ of consultants indicated they performed this type of cataract extraction.

The widely accepted opinion amongst the profession that extracapsular cataract extraction with a posterior chamber lens implant is the procedure of choice offered to patients with age-related cataract is confirmed by the findings.

Just over half of all the patients admitted had waited less than 6 months for their operation from the date that they had been listed for surgery. However, $17.3 \%$ of patients had been waiting 12 months or longer and of these $37 \%$ had waited for 18 months or more for surgery. These waiting times describe the experience of the individual patient. Routine Korner data returned to the Department of Health on waiting times is calculated from quarterly returns from regions from aggregates obtained from districts. Waiting time in this form indicates the number of patients waiting for treatment at the end of that particular quarter. It does not take account of the waiting time until treatment is undertaken and does not reflect the individual experience. By the end of September $198817 \%$ of all patients on ophthalmic waiting lists in England had been waiting 12 months or more for surgery. ${ }^{8}$ As the greater proportion of patients on ophthalmic waiting lists are those for cataract surgery, ${ }^{9}$ the national experience in 1990 does not appear to have changed.

The Survey has provided a great deal of information on the process and outcomes of cataract surgery, which will be described in subsequent papers in this series. Collectively these results will form the base for further studies on specific issues that influence the access, delivery and outcome of cataract surgery.

The Survey has also established the first step in the development of a national database for cataract surgery at the College of Ophthalmologists. It is planned to repeat the survey at 5-yearly intervals to provide regular evaluation of this common surgical intervention with changing surgical techniques, management policies and patient expectations. This database will be an important dynamic resource for the College of Ophthalmologists and all its members.

I am grateful to all the ophthalmologists who took part in this Survey and without whose support it would not have been possible; the staff at the College of Ophthalmologists; the Audit Secretary Miss Mahmood for her efficient organisation and assistance with management of the database; the Audit Committee of the College of Ophthalmologists and particularly the Chairman Professor Barrie Jay for his support and guidance throughout the project.

Key words: Cataract, Co-existing pathology, Process, Referral, Surgery, Visual impairment.

\section{REFERENCES}

1. Jay J, Devlin M: The increasing frequency of surgery for cataract. Eye 1990, 4: 127-31.

2. College of Ophthalmologists: Establishment of medical audit, 1990.

3.. Department of Health: Working for patients. London: HMSO, 1989.

4. Gardner SB, Winter PD, Gardner MJ: Confidence interval analysis. London: BMJ, 1989.

5. Pizzarello LD: The dimensions of the problem of eye disease among the elderly. Ophthalmology 1987, 94: 1191-5.

6. The Audit Commission for Local Authorities and the National Health Service in England and Wales: Audit Commission Review. October 1990.

7. Hodgkins PR, Luff AJ, Morrell AJ, Teye Botchway L, Featherstone TJ, Fielder A: Current practice of extraction and anaesthesia. Br J Ophthalmol 1992, 76: 323-6.

8. DHSS Hospital In-patient waiting lists-England. ISBN 1851974253.

9. Davidge M, Harley M, Vickerstaff L: The anatomy of large waiting lists. Lancet vol i, 1987, 794-6. 